\title{
Comparing tropical precipitation simulated by the Met Office NWP and climate models with satellite observations
}

Article

Published Version

Liu, C., Allan, R. P., Brooks, M. and Milton, S. (2014)

Comparing tropical precipitation simulated by the Met Office NWP and climate models with satellite observations. Journal of Applied Meteorology and Climatology, 53 (1). pp. 200-214. ISSN 1558-8424 doi: https://doi.org/10.1175/JAMC-D-13082.1 Available at https://centaur.reading.ac.uk/36247/

It is advisable to refer to the publisher's version if you intend to cite from the work. See Guidance on citing.

Published version at: http://journals.ametsoc.org/doi/pdf/10.1175/JAMC-D-13-082.1

To link to this article DOI: http://dx.doi.org/10.1175/JAMC-D-13-082.1

Publisher: American Meteorological Society

All outputs in CentAUR are protected by Intellectual Property Rights law, including copyright law. Copyright and IPR is retained by the creators or other copyright holders. Terms and conditions for use of this material are defined in the End User Agreement.

www.reading.ac.uk/centaur 
Central Archive at the University of Reading

Reading's research outputs online 


\title{
Comparing Tropical Precipitation Simulated by the Met Office NWP and Climate Models with Satellite Observations*
}

\author{
Chunlei LiU AND Richard P. Allan \\ Department of Meteorology, University of Reading, Reading, United Kingdom \\ MALCOLM BRoOKS AND SEAN Milton \\ Met Office, Exeter, United Kingdom
}

(Manuscript received 28 February 2013, in final form 23 August 2013)

\begin{abstract}
Forecasts of precipitation and water vapor made by the Met Office global numerical weather prediction (NWP) model are evaluated using products from satellite observations by the Special Sensor Microwave Imager/Sounder (SSMIS) and Tropical Rainfall Measuring Mission (TRMM) Multisatellite Precipitation Analysis (TMPA) for June-September 2011, with a focus on tropical areas $\left(30^{\circ} \mathrm{S}-30^{\circ} \mathrm{N}\right)$. Consistent with previous studies, the predicted diurnal cycle of precipitation peaks too early (by $\sim 3 \mathrm{~h}$ ) and the amplitude is too strong over both tropical ocean and land regions. Most of the wet and dry precipitation biases, particularly those over land, can be explained by the diurnal-cycle discrepancies. An overall wet bias over the equatorial Pacific and Indian Oceans and a dry bias over the western Pacific warm pool and India are linked with similar biases in the climate model, which shares common parameterizations with the NWP version. Whereas precipitation biases develop within hours in the NWP model, underestimates in water vapor (which are assimilated by the NWP model) evolve over the first few days of the forecast. The NWP simulations are able to capture observed daily-to-intraseasonal variability in water vapor and precipitation, including fluctuations associated with tropical cyclones.
\end{abstract}

\section{Introduction}

The realistic representation of precipitation in weatherforecasting and climate-prediction models is of importance to society in terms of planning for and reducing damage from extreme weather (Meehl et al. 2007; O'Gorman and Schneider 2009; Kendon et al. 2012). Projected intensification in precipitation (Sun et al. 2007; Kharin et al. 2007; Allan et al. 2013; O'Gorman 2012; Liu and Allan 2013) and drying of dry subtropical regions (Power et al. 2012; Scheff and Frierson 2012; Allan et al. 2013) are caveated by unrealistic representation of moist processes and systematic biases in climate simulations (e.g., Liu et al. 2012; John and Soden 2007; Pierce et al. 2006) that also impact the

\footnotetext{
* Supplemental information related to this paper is available at the Journals Online website: http://dx.doi.org/10.1175/JAMC-D-13-082.s1.

Corresponding author address: Dr. Chunlei Liu, Dept. of Meteorology, University of Reading, Reading RG6 6BB, United Kingdom. E-mail: c.l.liu@reading.ac.uk
}

skill of weather forecasts (Williams and Brooks 2008). Forecasting over short time periods is vital since it is important to make decisions a few days in advance for agriculture, water resources, and health authorities, which are dependent on accurate forecasts of precipitation from routine numerical weather prediction (NWP).

Many of these forecast errors are associated with diurnal phase and intensity (Dai 2001; Dai and Trenberth 2004), particularly over regions with intense precipitation (Chakraborty 2010). The diurnal cycle involves many coupled processes, such as surface exchange, turbulence, convection, and cloud-radiation interactions (Bechtold et al. 2004), which are all parameterized in both NWP and climate models, which share the same physical structure (Brown et al. 2012), and therefore identifying emerging biases over the first few days of NWP forecasts can illuminate the processes responsible for systematic biases in climate-model simulations (Slingo et al. 2003; Pierce et al. 2006; John and Soden 2007; Rodwell and Palmer 2007; Martin et al. 2010; Xie et al. 2012).

In this study the global precipitation forecast by the Met Office global NWP model (Walters et al. 2011) is 
compared with satellite observations, with a concentration on tropical regions $\left(30^{\circ} \mathrm{N}-30^{\circ} \mathrm{S}\right)$. The main objectives are 1) to investigate the diurnal-cycle phase and amplitude effect on the biases and 2) to understand the evolution of the model biases and identify any links to similar biases in the Hadley Centre Global Environment Model, version 2 (HadGEM2), which is the model's climate configuration (Martin et al. 2011).

\section{Datasets and method}

The NWP model data are obtained from the Met Office global NWP system (Brown et al. 2012) for the period from June to September 2011. The forecast model during this period was configured as the Global Atmosphere 3.1 model described in Walters et al. (2011). The data used in this study are from forecasts initialized at 1200 UTC using the hybrid ensemble four-dimensional variational data assimilation scheme described in Clayton et al. (2012) and Rawlins et al. (2007). The data used are instantaneous (model time step) snapshots from 0 (1200 UTC day 0) to 144 (1200 UTC day 6) h. The data are available at 3 -h intervals until $72 \mathrm{~h}$ and then at 12 -h intervals to $144 \mathrm{~h}$. The daily mean of day 0 is defined as the averaged output in the first $24 \mathrm{~h}$ (from 1200 , 1500, 1800, 2100, 0000, 0300, 0600, and 0900 UTC). The average from the next $24 \mathrm{~h}$ of outputs is defined as the mean of day 1 , and so on. In this way, the first three daily means will contain eight forecasts in each day. The following days (3-6) contain only forecasts at 1200 and 0000 UTC. The corresponding Tropical Rainfall Measuring Mission (TRMM) Multisatellite Precipitation Analysis (TMPA) 3-hourly data are also organized similarly for bias and diurnal-cycle calculations.

Most of the products from satellite measurements sampling instantaneous rainfall rates over 1-2 overpasses per day may be considered as instant snapshots of the precipitation fields averaged over the satellite footprints. The latest (version 7) precipitation and water vapor retrieved from the Special Sensor Microwave Imager/Sounder (SSMIS) by the Remote Sensing Systems company (RSS) using a unified, physically based algorithm (Hilburn and Wentz 2008) are daily data. It is not ideal to compare them with NWP data directly because of their spatial and temporal coverage, but they are assimilated to the NWP model, and therefore the comparisons may provide some information on the model behavior. The precipitation data from TMPA (Huffman et al. 2007), blended from a variety of sources (including rain gauges over land) and having both daily and 3-hourly output, can be used for mean skill and diurnal-cycle comparisons with the NWP model.
Precipitation $P$ and total column water vapor content WV from the climate models HadGEM2-ES (Earth System configuration) and HadGEM2-A (Atmosphere Only configuration) (Martin et al. 2011) are also used to compare the climatological biases with the biases emerging from NWP simulations. The climate-model data were obtained from phase 5 of the Coupled Model Intercomparison Project (CMIP5; K. E. Taylor et al. 2012) and phase 5 of the Atmospheric Model Intercomparison Project (AMIP5; the atmosphere-only experiments) archives. HadGEM2-A is forced by realistic sea surface temperature (SST) and sea ice and radiative forcings. The total column water vapor data from the interim European Centre for Medium-Range Weather Forecasts (ECMWF) reanalysis product (ERA-Interim; Dee et al. 2011) are also used here for comparison purposes. It is accumulated from 6-hourly data with $0.25^{\circ}$ latitude and longitude resolution interpolated from the original N128 reduced Gaussian grid $\left(\sim 0.7^{\circ}\right)$. Both radiances from the Special Sensor Microwave Imager (SSM/I) and High-Resolution Infrared Radiation Sounder (HIRS) related to the total column water vapor are assimilated into the ERA-Interim data. All datasets and their brief descriptions are listed in Table 1; the products retrieved from the SSM/I on F13 and the SSMIS on F17 are named RSS F13 and RSS F17, respectively.

For precipitation and water vapor products from satellite observations, it must be borne in mind that, although the observations are normally regarded as "truth," the observational data themselves have some uncertainties, such as the discrepancies between the TRMM 3B42 and TRMM 3G68 datasets (Kikuchi and Wang 2008) and between TRMM 3B42 and data from the TRMM precipitation radar (Kidd et al. 2013). It is known that the TRMM precipitation retrieval algorithm includes distinctly different methods for land and ocean (Kummerow et al. 2001). The reanalysis can be regarded as data that are close to the truth, but it still involves some model tuning and therefore may not represent the "true truth." The NWP data are instantaneous, which differs from the observed data, such as the TMPA 3-hourly data representing 3-h means from different sources. All of these factors need to be considered when comparisons are made.

Because the Met Office NWP model grid is not the same as those from satellite observational datasets, when calculating the bias and correlations all data are interpolated to a $1^{\circ} \times 1^{\circ}$ resolution box by simply taking the mean of all valid data points in that box or the average of the four neighboring grid points closest to the box center if there is no data point in that $1^{\circ} \times 1^{\circ}$ box. As in Chakraborty (2010), the root-mean-square error (RMSE) in space is calculated as 
TABLE 1. Datasets and their properties.

\begin{tabular}{|c|c|c|}
\hline Dataset & Resolution lat $\times$ lon & Description \\
\hline Met Office NWP & $0.234375^{\circ} \times 0.3515625^{\circ}$ & 3 hourly for global ocean and land; forecasts up to 7 days \\
\hline RSS F13 v7 & $0.25^{\circ} \times 0.25^{\circ}$ & Daily, global ice-free ocean (http://www.remss.com/ssmi/ssmi_description.html) \\
\hline RSS F17 v7 & $0.25^{\circ} \times 0.25^{\circ}$ & Daily, global ice-free ocean (http://www.remss.com/ssmi/ssmi_description.html) \\
\hline TMPA & $0.25^{\circ} \times 0.25^{\circ}$ & $\begin{array}{l}\text { Daily and } 3 \text { hourly; ocean and land covering } 50^{\circ} \mathrm{N}-50^{\circ} \mathrm{S} \\
\text { (http://trmm.gsfc.nasa.gov/3b } 42 . \mathrm{html} \text { ) }\end{array}$ \\
\hline ERA-Interim & $0.25^{\circ} \times 0.25^{\circ}$ & $\begin{array}{l}6 \text { hourly for global ocean and land; interpolated from the original N128 reduced } \\
\text { Gaussian grid }\left(\sim 0.7^{\circ}\right)\end{array}$ \\
\hline HadGEM2-A & $1.25^{\circ} \times 1.87^{\circ}$ & AMIP5 data; atmospheric model only, with prescribed SST and sea ice \\
\hline HadGEM2-ES & $1.25^{\circ} \times 1.87^{\circ}$ & CMIP5 data; coupled model; realistic radiative forcings \\
\hline
\end{tabular}

$$
\mathrm{RMSE}=\left[\frac{\sum_{i, j=1}^{N, M}\left(M_{i, j}-O_{i, j}\right)^{2}}{N M}\right]^{1 / 2},
$$

where $N$ and $M$ are the total number of points in space, and $M_{i, j}$ and $O_{i, j}$ are model and observed fields at the $i$ th and $j$ th location. The bias is defined as

$$
\operatorname{bias}=\frac{\sum_{k=1}^{K}\left(M_{k}-O_{k}\right)}{K},
$$

where $K$ is the total number of data points and $k$ can be the time or location.

\section{Characterization of NWP model biases in precipitation and water vapor}

The seasonal means of precipitation and total column water vapor content over the period of June-September 2011 (hereinafter JJAS 2011) from both model and observations are shown in Fig. 1 in their original grid. The mean precipitation features of the intertropical convergence zone (ITCZ) are captured by the NWP model at day 0 when compared with the RSS F17 and TMPA data. The RSS F17 data show weaker precipitation over the central Indian Ocean than do the other two datasets (see Figs. S1a-c of the supplemental material) but stronger precipitation over the North Pacific and North Atlantic Ocean storm regions. The observational datasets are subject to calibration and sampling uncertainties (e.g., the agreement of precipitation among different datasets is typically within $\pm 3 \%$; Hilburn and Wentz 2008), which may also contribute to the differences. The observed water vapor is assimilated by the NWP model, which maintains generally good agreement with RSS F17, and the ERA-Interim analysis, although the NWP is slightly wetter $(\sim 3 \%)$ than the other two datasets (see Figs. S1d and S1e of the supplemental material).

Because the tropical and subtropical regions $\left(30^{\circ} \mathrm{N}-\right.$ $\left.30^{\circ} \mathrm{S}\right)$ are the primary precipitation regions and are covered by both the RSS F17 (ocean only) and TMPA (ocean and land) datasets, the following analysis will focus on this area. The mean predicted instantaneous precipitations at 0000 and 1200 UTC day 0 calculated from averages of all precipitations at 0000 and 1200 UTC day 0 over JJAS 2011 and the biases between NWP and TMPA are plotted in Fig. 2, together with the mean streamfunction at 1200 UTC day 0 . Over equatorial Africa, the wet NWP bias at 1200 UTC day 0 (Fig. 2e) increases with lead time (Figs. 2g,j), whereas the dry bias at 0000 UTC weakens throughout the period (Figs. 2d,f,i). Over southern Asia, there is a wet precipitation bias at 0000 UTC that weakens slightly with lead time and a larger-magnitude dry bias at 1200 UTC that strengthens slightly with time. A wet bias over the $\mathrm{Pa}$ cific ITCZ and northwestern subtropical Pacific at 1200 UTC day 0 (Fig. 2e) weakens by day 1 (Fig. 2g). At 0000 UTC, the wet bias over the Pacific ITCZ is small in comparison with that at 1200 UTC because of light precipitation intensity at 0000 UTC. The slightly dry bias at 0000 UTC is around the western Pacific warm pool initially, but it develops quickly with lead time, and a wet bias develops in the Indian Ocean (Figs. 2d,f,i).

The dry biases over central Africa are from 1500 to 0600 UTC, and the wet biases are from 0900 to 1200 UTC (supplemental Figs. S2 and S3). The dry biases over Central America are from 2100 to 1200 UTC, and the wet biases are from 1500 to 1800 UTC (supplemental Figs. S2 and S3). In general, biases for later days resemble the structure of biases at day 0 , although it is likely that land surface feedbacks may strengthen equatorial precipitation biases over the period (Williams et al. 2012; C. M. Taylor et al. 2012). Many of these contrasting biases over land at 0000 and 1200 UTC relate to errors in the diurnal cycle that will be discussed in the next section. The streamfunction is a useful parameter to relate the precipitation biases to the circulation, especially in the tropics. The mean (nondivergent) flow is along lines of constant streamfunction (streamlines); a positive streamfunction indicates anticyclonic flow in the Northern Hemisphere and cyclonic flow in the 
Precipitation ( $\mathrm{mm} /$ day)
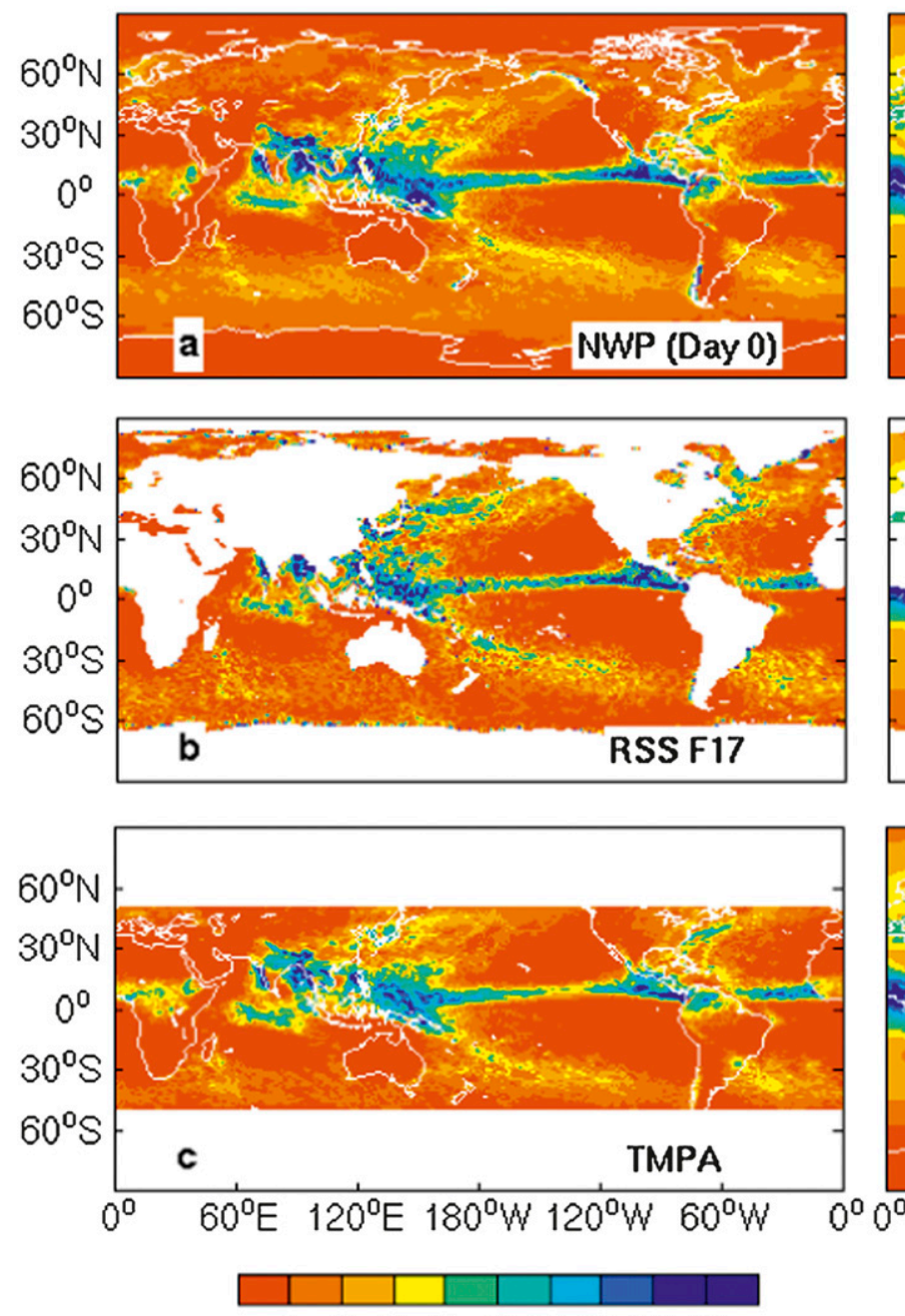

$\begin{array}{lllllllll}2 & 4 & 6 & 8 & 10 & 12 & 14 & 16 & 18\end{array}$
Water Vapour (mm)
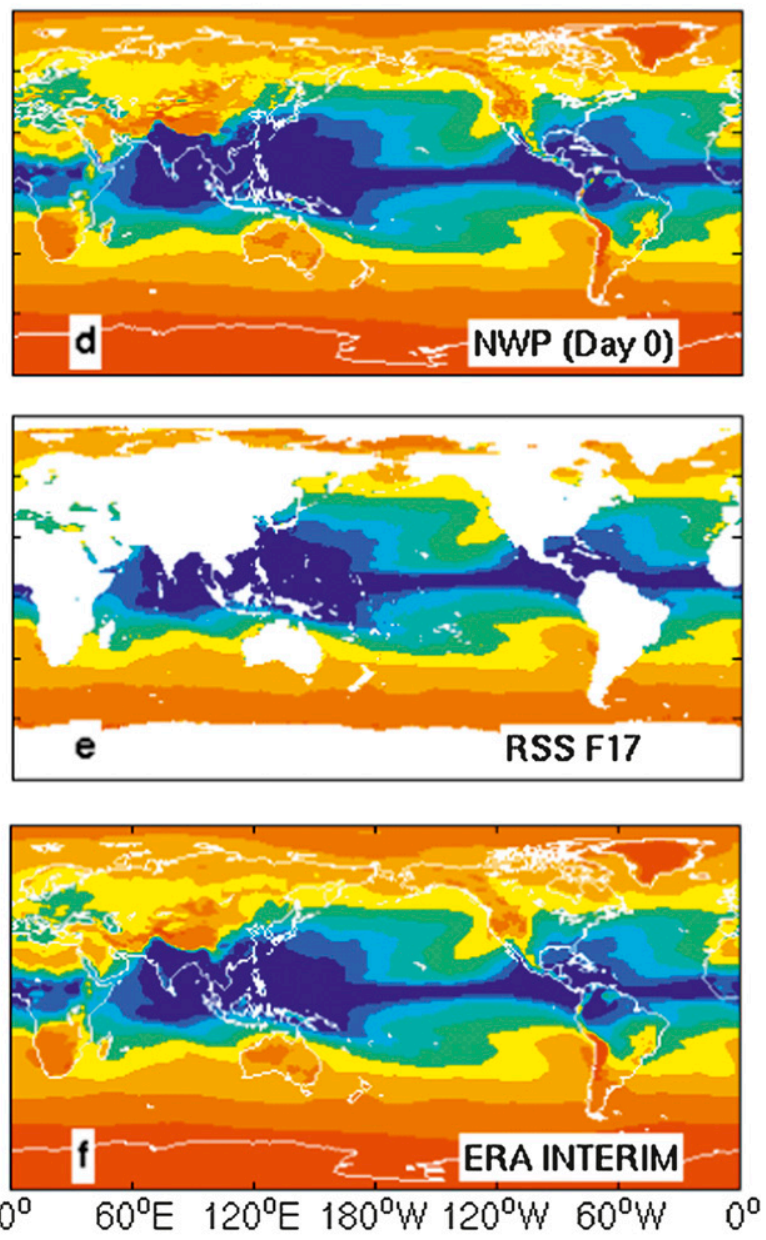

61218243036424854

FIG. 1. (left) Mean precipitation ( $\mathrm{mm} \mathrm{day}^{-1}$ ) and (right) total column water vapor content (mm) averaged over June-September 2011 from day 0 of (a),(d) the NWP model, (b),(e) RSS F17, (c) TMPA, and (f) ERA-Interim.

Southern Hemisphere. The mean circulation in Fig. 2c shows prominent subtropical anticyclones in both hemispheres, and the anticyclonic circulation in the Indian Ocean is the Indian monsoon. The streamfunction differences relative to the streamfunction at day 0 (Figs. $2 \mathrm{~h}, \mathrm{k}$ ) are relatively small but show the Indian monsoon circulation slightly strengthening and drifting northward. This strengthening circulation would enhance the moisture fluxes into the Indian subcontinent, and therefore the observed increase in the dry bias in this region is inconsistent with the bias being driven by circulation errors alone. Over Africa, the strengthening of the streamfunction on day 5 brings moisture from the western Indian Ocean, resulting in the weakening of the dry bias at 0000 UTC and the enhancement of the wet bias at 1200 UTC.
To investigate the bias evolution, spatial RMSEs, spatial Pearson correlation coefficient, and mean biases at 0000 and 1200 UTC between NWP and TMPA data are calculated over the tropical $\left(30^{\circ} \mathrm{S}-30^{\circ} \mathrm{N}\right)$ ocean and land separately based on the seasonal mean of JJAS 2011 (Fig. 3). The RMSE in Fig. 3a over the tropical land at 1200 UTC is much higher than that over the ocean, and it is mainly contributed by the wet bias over Africa and dry bias over Asia (see Figs. 2e,j). The corresponding bias (Fig. 3c) is low because of contrasting contributions from these two regions. The drop of RMSE from day 0 to day 1 over the ocean at 1200 UTC implies an adjustment of the model toward its own climatological values, in response to corrections applied by the data assimilation system. This drop is also reflected in the bias calculation (Fig. 3c) and is associated 

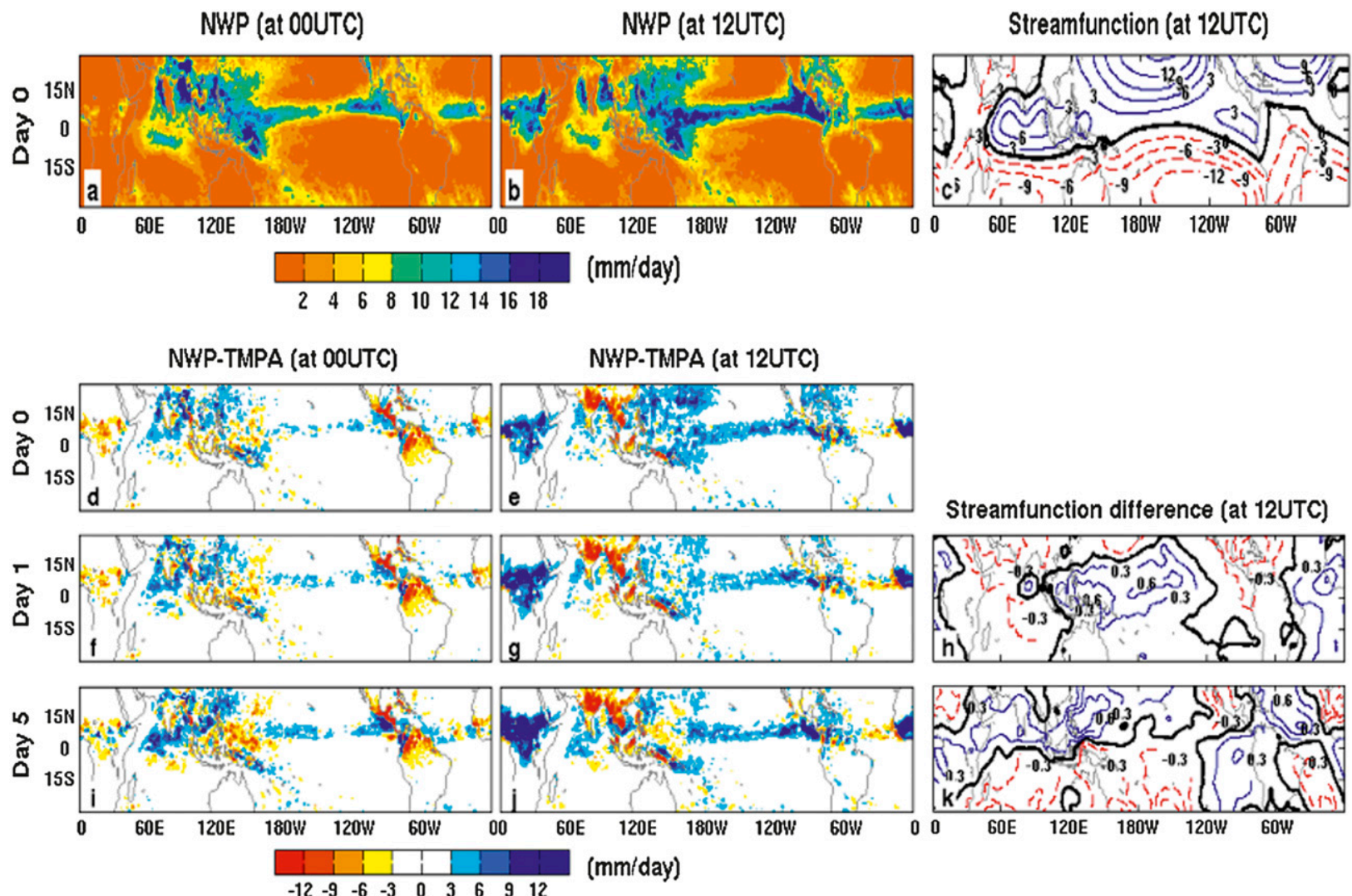

FIG. 2. Mean precipitation of day 0 at (a) 0000 and (b) 1200 UTC; (c) mean 10-m streamfunction $\left(10^{-6} \mathrm{~m}^{2} \mathrm{~s}^{-1}\right)$ at $1200 \mathrm{UTC}$; (d)-(g), (i),(j) precipitation biases between the model and TMPA at different lead days; (h), (k) streamfunction differences relative to the streamfunction at 1200 UTC day 0. All data are averaged over the period from June to September 2011.

with the northwestern Pacific region (Figs. 2e,g). The RMSEs over the ocean at both 0000 and 1200 UTC are comparable except for day 0.

The growth in RMSE over the land is very different at 0000 and 1200 UTC, with the error growth being largest in 1200 UTC forecasts over land because of large biases over Africa and Asia (supplemental
Fig. S5). The differences between the 0000 and 1200 UTC forecasts are dominated by biases over the Pacific where 1200 UTC coincides with the peak convective activity around 0000-0300 local time (LT) for the model and 0300-0600 LT for TMPA; this is explained by the diurnal cycle, which is discussed further in section 4.
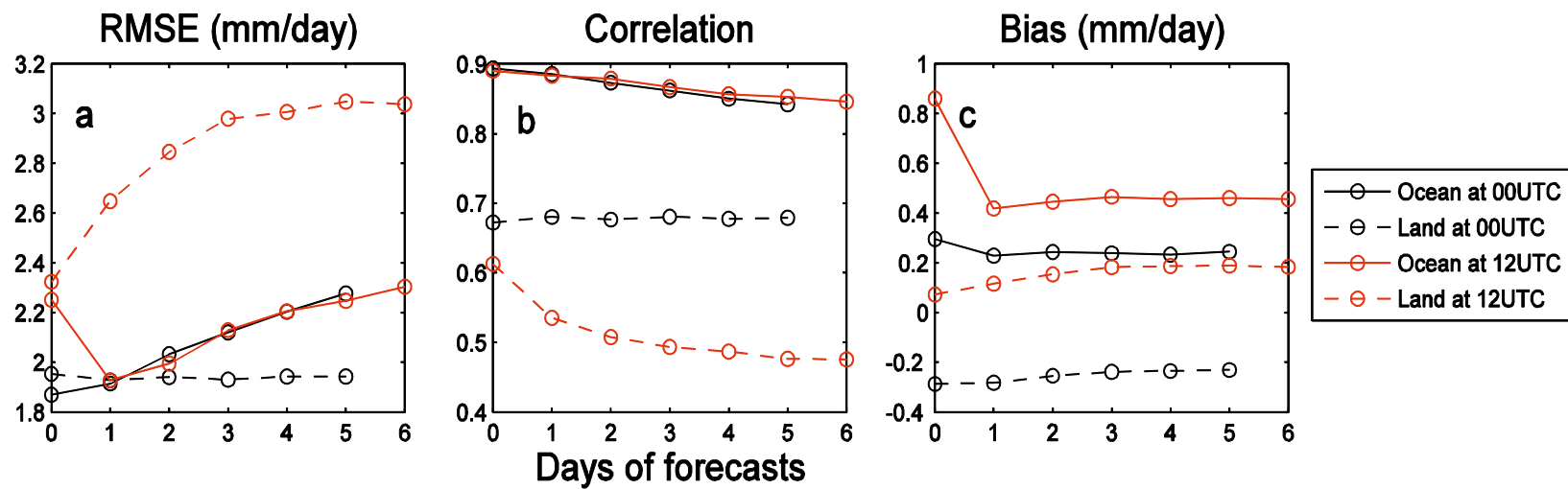

FIG. 3. Variation of (a) spatial RMSEs, (b) spatial correlation coefficients, and (c) mean biases between NWP and TMPA at 0000 and 1200 UTC with forecast lead time over the tropical oceans and land. 
$P$ difference $(\mathrm{mm} /$ day at $12 \mathrm{UTC})$
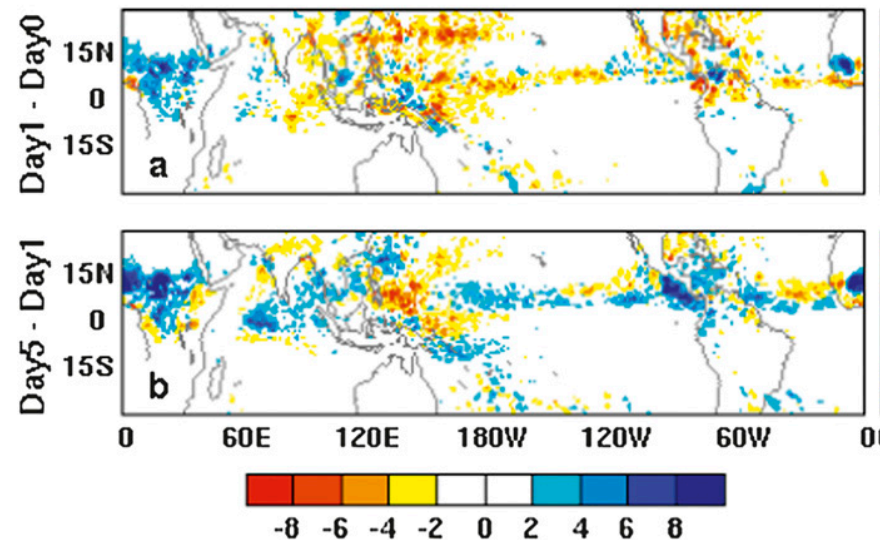

WV difference $(\mathrm{mm}$ at $12 \mathrm{UTC})$
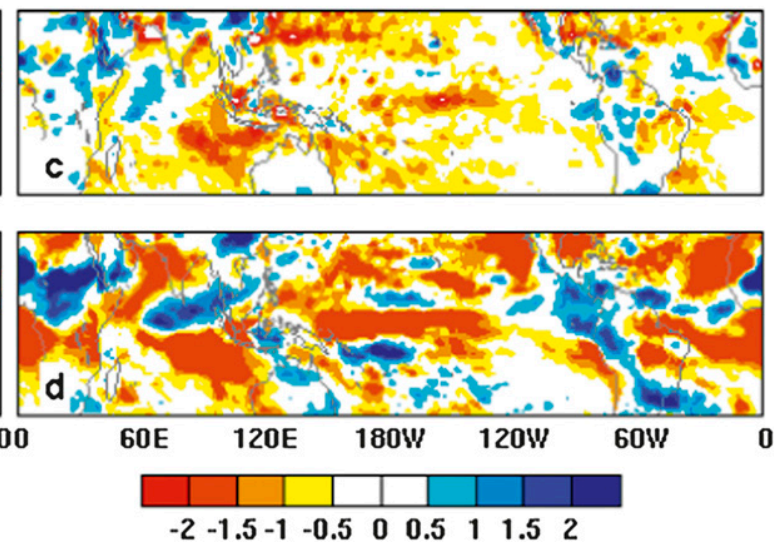

FIG. 4. Differences of NWP (a),(b) mean precipitation $\left(\mathrm{mm} \mathrm{day}^{-1}\right)$ and (c),(d) mean total column water vapor content (mm) (top) between day 1 and day 0 at 1200 UTC and (bottom) between day 5 and day 1 at 1200 UTC. Data are averaged from June to September 2011.

The spatial correlations over the tropical ocean at both 0000 and 1200 UTC are very high and consistent (Fig. 3b). The correlation over land at 1200 UTC is low, but the bias (Fig. 3c) is also low. This situation implies that the precipitation over the tropical land at 1200 UTC is out of phase (see Fig. 5 below).

The drop of RMSE and bias over the tropical oceans from day 0 to day 1 at 1200 UTC also applies at 1500 UTC, and the drop for both RMSE and bias continues at 1800 and 2100 UTC over the western Pacific, eastern Pacific, and Atlantic but is mixed over land areas (see supplemental Figs. S4 and S5). For RMSE at 1200 UTC over the tropical land, there is no obvious drop from day 0 to day 1 . Only over Africa does the RMSE decrease from day 0 to day 2 from 1800 to 0600 UTC (supplemental Fig. S5). The 0000 and 1200 UTC area-mean statistics in Fig. 3 have contributions from different places with different solar times (local time); the details for each area can be seen from Figs. S4 and S5 of the supplemental material.

To investigate the adjustment from day 0 to day 1 and the trend over the forecast period, the differences of precipitation and total column water vapor content from NWP simulations between day 1 and day 0 and between day 5 and day 1 at 1200 UTC are plotted in Fig. 4, indicating the trend over different areas. There is a big drop in precipitation from day 0 to day 1 at 1200 UTC over southeastern Asia, the western Pacific, the Pacific ITCZ, and North American regions (see Fig. 4a); this is consistent with the change of water vapor content, which shows decreases over most tropical ocean regions (Fig. 4c), although it is not clear which bias develops first. The decrease of precipitation over the western Pacific continues to day 5, and the water vapor also decreases quickly; this is reflected by the reduced bias with lead time over the western Pacific (supplemental Fig. S4). This result means that the NWP-simulated precipitation is too high after assimilation over the western Pacific at 1200 UTC. This will be further investigated in the next section. Both precipitation and water vapor content increase over Africa between $0^{\circ}$ and $15^{\circ} \mathrm{N}$, consistent with the increased RMSE and bias over this region (supplemental Fig. S5). It is plausible that the enhanced moisture flow (Fig. 2k) will increase precipitation over equatorial Africa and further enhance soil moisture, evaporation, and atmospheric water vapor, thereby initiating a positive feedback on the precipitation changes.

\section{The diurnal cycle of precipitation}

The diurnal cycle of precipitation is the response to the solar diurnal-cycle forcing, and it is the main source of forecast error (Chakraborty 2010). Proper representation of the interactions among the various elements of the atmosphere-land-ocean-cryosphere system is crucial for achieving the correct amplitude and phase of this forced diurnal cycle (Bergman and Salby 1996; Yang and Slingo 2001; Kikuchi and Wang 2008). To investigate the diurnal-cycle effect on the precipitation bias, the 3-hourly data from TMPA are used for comparison with NWP data.

The area mean diurnal cycle from June to September 2011 over five tropical ocean regions and four tropical land regions (see Table 2) is calculated and is displayed in Fig. 5. The hours at the bottom of each plot are local time for the area center, and those at the top of the plot are in UTC. The full diurnal cycle for days $0-2$ and data points at 0000 and 1200 UTC from days 3 to 6 are also plotted, together with observations from TMPA 3-hourly datasets. The lines for days $0-2$ are broken between 
TABLE 2. Areas used for regional study of the diurnal cycle, RMSEs, correlations, and biases. The region's latitude range is from $30^{\circ} \mathrm{N}$ to $30^{\circ} \mathrm{S}$ unless specified.

\begin{tabular}{lcc}
\hline \hline Region name & Region & Land/Ocean \\
\hline Indian Ocean & $25^{\circ}-100^{\circ} \mathrm{E}$ & Ocean \\
Western Pacific & $120^{\circ} \mathrm{E}-150^{\circ} \mathrm{W}$ & Ocean \\
Central Pacific & $170^{\circ} \mathrm{E}-135^{\circ} \mathrm{W}$ & Ocean \\
Eastern Pacific & $135^{\circ}-85^{\circ} \mathrm{W}$ & Ocean \\
Atlantic & $70^{\circ} \mathrm{W}-17^{\circ} \mathrm{E}$ & Ocean \\
Africa & $23^{\circ} \mathrm{W}-60^{\circ} \mathrm{E}$ & Land \\
Asia & $30^{\circ} \mathrm{N}-6.8^{\circ} \mathrm{S}, 62^{\circ}-125^{\circ} \mathrm{E}$ & Land \\
Australia & $11.5^{\circ}-30^{\circ} \mathrm{S}, 112^{\circ}-162^{\circ} \mathrm{E}$ & Land \\
America & $120^{\circ}-35^{\circ} \mathrm{W}$ & Land \\
\hline
\end{tabular}

0900 and 1200 UTC to indicate the discontinuity of the time from the definition of days 0,1 , and 2 in section 2 .

The peaks in the predicted diurnal cycle over the oceans are in the early morning $(\sim 0100-0600 \mathrm{LT})$, and they are approximately $3 \mathrm{~h}$ earlier than observations based on the available data temporal resolution. The amplitudes from models are larger than indicated by TMPA data. Over most of the ocean regions considered (four out of five), the peak from day 0 is higher than those at longer forecast lead time, relating to the initial response of the assimilation increments in these regions. The diurnal-cycle shape and amplitude for forecasts at different lead times are very similar except that of day 0 .

Over land, the NWP peak position is also ahead of those of the observations. The model shows peaks around local noon, but the observations show peaks around 1500-1800 LT, consistent with previous analysis (Yang and Slingo 2001; Bechtold et al. 2004; Rasch et al. 2006; Dai et al. 2007; Stratton and Stirling 2012). Overall, the mean diurnal phases over different ocean and land areas from the NWP simulations are stable with lead time, in contrast to those studied by Chakraborty (2010) using the ECMWF model over the Indian monsoon area, where the phase error in the diurnal cycle increases from day 0 to day 1 .

Most of the biases over land areas in Fig. 2 can be explained by the phase difference of the diurnal cycle. Over central Africa around 0000 UTC, the observed precipitation is higher than values from the NWP forecasts, which increase with the lead time (Fig. 5f). This result explains the dry bias and the weakening of the bias with lead time at 0000 UTC. The diurnal-cycle magnitude from NWP is much higher at 1200 UTC than that from observations, and therefore we see the wet bias at 1200 UTC in Fig. 2. There is a bimodal variation of diurnal cycle over Australia in the TMPA data, but the model misses the earlier peak (Fig. 5h). The bias is still small in Fig. 2 because of the small precipitation amplitude over Australia (note that the scales of the $y$ axes in Fig. 5 vary by panel). The mean biases over the western Pacific are mixed (wet and dry) in Fig. 2 (see also Figs. S2 and S3 of the supplemental material), but the mean diurnal-cycle amplitude from the model is always higher than the observations (Fig. 5b). This situation implies ITCZ dominance of the area-weighted precipitation amplitude.

While increasing resolution helps in improving the characteristics of the diurnal cycle in precipitation (Kendon et al. 2012), errors in the phase and spatial organization of convective systems are ultimately tied to convective parameterization (Pearson et al. 2013), which is necessary at all but the finest-scale simulations (e.g., $1 \mathrm{~km}$ ). Modifications to the convective parameterization may be used to improve the simulation of radiative energy budget (Allan et al. 2007) and the diurnal amplitude and timing of precipitation (Stratton and Stirling 2012). Furthermore, the data from observations have their own uncertainties (Kikuchi and Wang 2008). Although afternoon peak time over land is physically understandable, the mechanism for early peak time over the ocean is still not very clear (Kidd et al. 2013), and further investigation is needed.

\section{Comparison with systematic climate-model bias}

In this section, we characterize the daily mean precipitation and water vapor errors in the NWP simulations and attempt to link with systematic biases in the climate-model version. The mean precipitation bias between NWP and TMPA data is plotted in Figs. 6a,b at day 0 and day 2 . The data are averaged from daily means (eight values per day) over JJAS 2011. There are dry mean precipitation biases over central Africa at day 0 , but they become wet at day 2 . There are wet biases over Asia, the northern Indian Ocean, the western Pacific, and the Pacific ITCZ, although dry biases develop over the western Pacific by day 2.

Because water vapor is the source of precipitation and it is assimilated by the model, the bias of total column water vapor content between NWP (at day 0 and day 2) and ERA-Interim data is also shown in Figs. 6c,d. The whole tropical area is dominated by the wet biases except those areas around central Africa. The bias is reduced at day 2 in general, and some dry biases have developed over South America, the central Pacific, and India. The bias trend over central Africa is similar to that of precipitation and evolved from dry to wet, again indicating coupling and potential positive feedbacks.

The water vapor biases between NWP and RSS F17 in Figs. 6e,f also show similar tendencies. The biases are smaller than those from ERA-Interim since the water vapor content in ERA-Interim is lower than other 

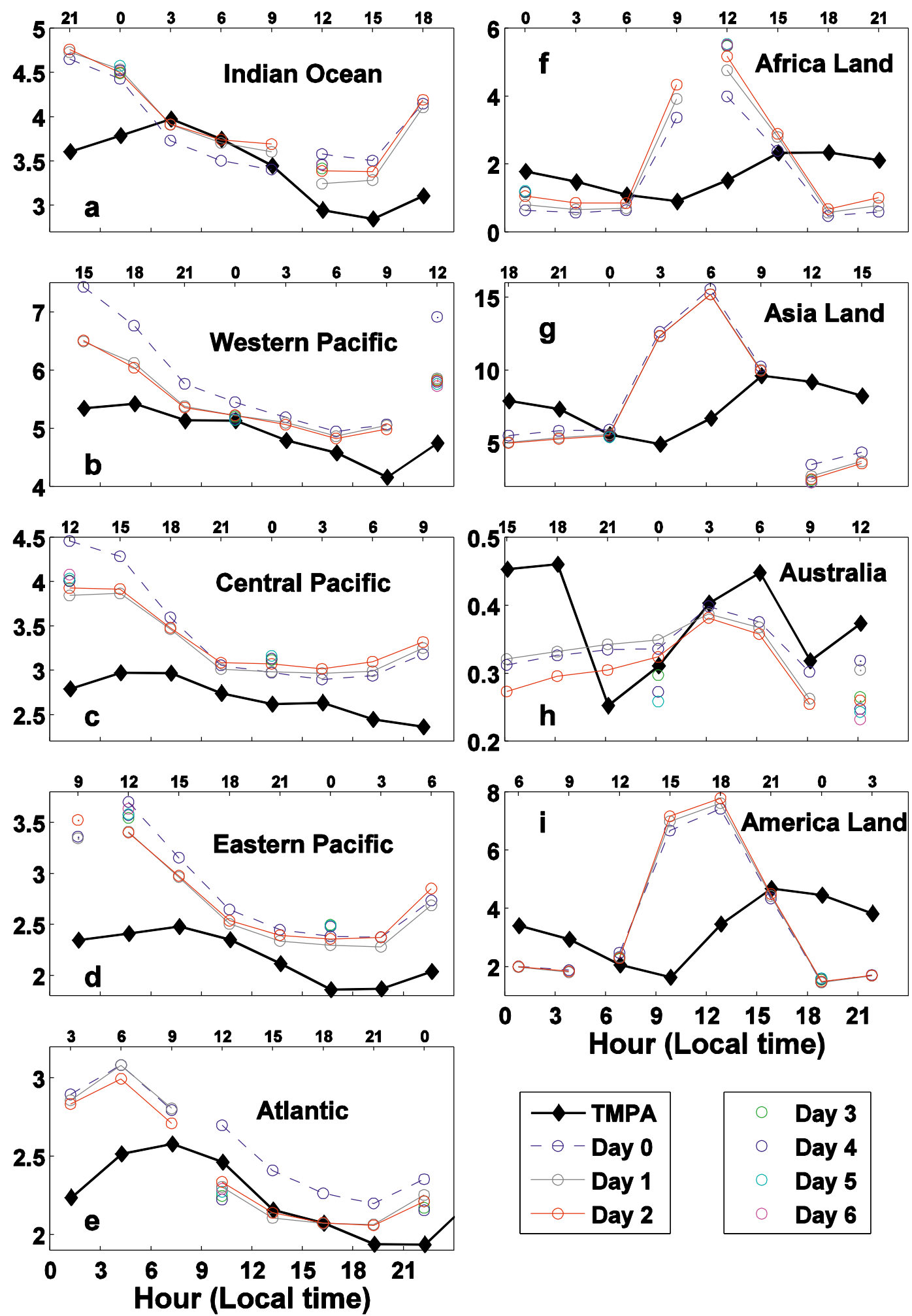

FIG. 5. Area-mean precipitation diurnal cycle over (a)-(e) the tropical ocean areas and (f)-(i) the tropical land areas for the period from June to September 2011. The time at the top of each plot is in UTC based on the time at the center of that region. The line broken for days 0-2 between 0900 and 1200 UTC indicates the discontinuity of the time from the definition of days 0,1 , and 2 in section 2 . 

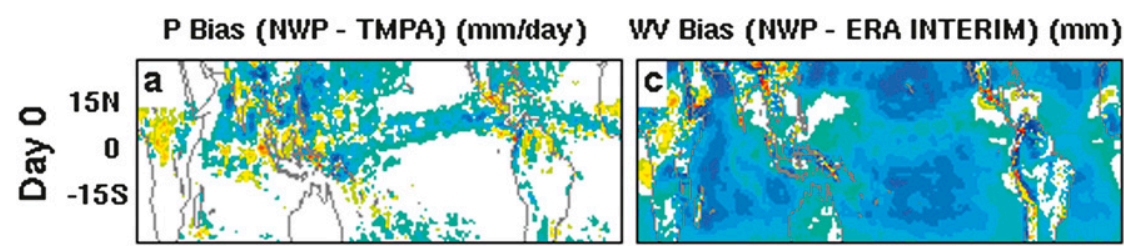

WN Bias (NWP - RSS F17) (mm)
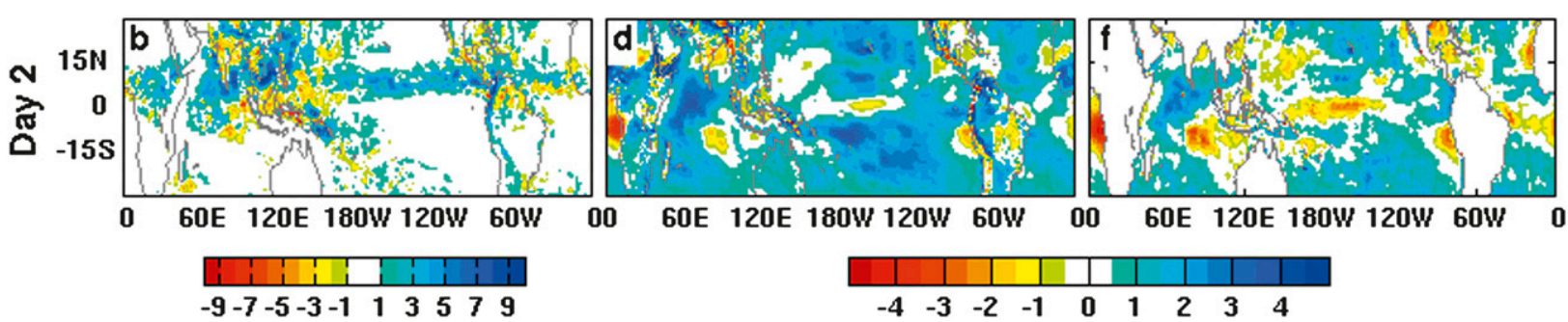

FIG. 6. Mean precipitation and total column water vapor content difference at days 0 and 2: (a),(b) precipitation difference between NWP and TMPA, (c),(d) water vapor content difference between NWP and ERA-Interim data, and (e),(f) water vapor content difference between NWP and RSS F17 data. The data are averaged from June to September 2011.

observations over the subtropical oceans (Dee et al. 2011). There are some differences between precipitation bias (Fig. 6b) and water vapor content bias (Fig. 6f), such as the wet-bias domination over the whole tropical oceans; this may result from the longer time scale over which assimilated water vapor reaches equilibrium. In general, the NWP model progresses toward to a drier climate over the oceans while the bias over central Africa progresses toward to a wetter climate.
The Met Office NWP model uses a set of parameterizations that is similar to the climate version of the HadGEM2 model. To investigate whether the bias emerging from the NWP simulations relates to the climatological difference between the climate model and the observations, the climatological differences of precipitation and water vapor content are plotted in Fig. 7.

The climatological differences between HadGEM2-A (atmospheric model only) and observations are shown in
HadGEM2-A 2000-2008
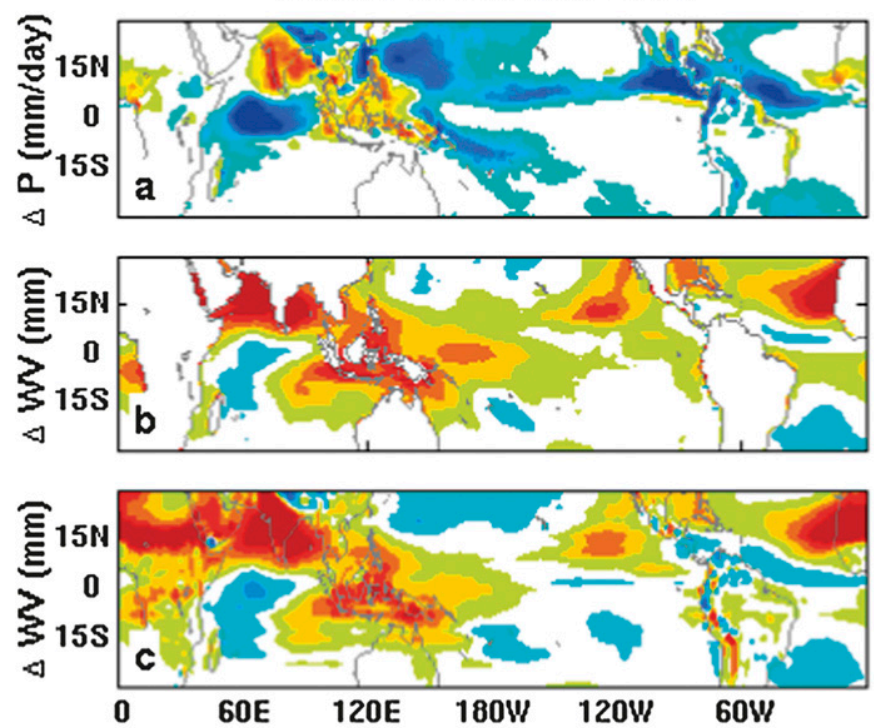

HadGEM2-ES 1998-2005
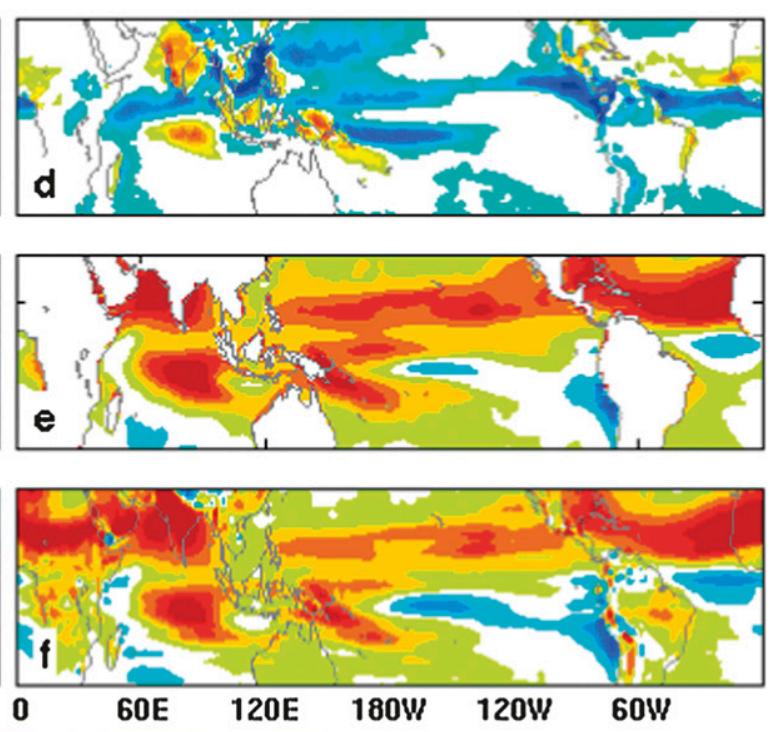

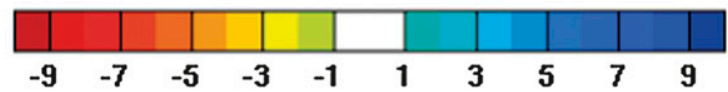

FIG. 7. Mean precipitation difference $(\Delta P)$ and total column water vapor content difference $(\Delta \mathrm{WV})$. The data are averaged over (left) June-September of 2000-08 and (right) from 1998 to 2005. Shown are (a) P(HadGEM2-A) - P(TMPA), (b) WV(HadGEM2-A) WV(RSS F13), (c) WV(HadGEM2-A) - WV(Interim), (d) P(HadGEM2-ES) - P(TMPA), (e) WV(HadGEM2-ES) - WV(RSS F13), and (f) WV(HadGEM2-ES) - WV(Interim). 
Figs. 7a-c. The climatological mean is calculated over the period of June-September from 2000 to 2008. The general overestimation of precipitation over the tropical oceans is similar to the mean biases among many AMIP5 models (Liu et al. 2012). The HadGEM2-A precipitation biases are qualitatively consistent with the NWP and TMPA differences shown in Fig. 6b, but there are no strong biases over central Africa. Brown et al. (2012) also find similarities between NWP and HadGEM2 biases using Global Precipitation Climatology Project observations for annual mean data. The dry water vapor biases are over tropical Asia and the western Pacific when compared with RSS F13 data, and the pattern is similar to the bias between HadGEM2-ES and ERA-Interim (Figs. 7c,f) and the NWP biases (Fig. 6f). Some similarities of the dry bias areas over land can be seen between HadGEM 2 and the NWP model (Fig. 6d and Fig. 7c), such as the dry biases over North Africa around $15^{\circ} \mathrm{N}$ and over India, central Asia, and North America. Over the ocean there are more similarities between Fig. 6f and Fig. 7b, such as the dry biases over the western Pacific, northwestern Pacific, and eastern Indian Ocean and the wet bias over the western Indian Ocean.

The climatological differences between HadGEM2ES and observations are shown in Figs. 7d-f. In these simulations, the SST is free to evolve and therefore adds the potential for additional positional errors in the large-scale atmospheric circulation. For precipitation, however, the bias over the western Pacific is similar to that between HadGEM2-A and TMPA. The smaller biases in HadGEM2-ES are associated with the coupled ocean-atmosphere response to the bias: the coupled model tends to develop a cool SST bias, in part relating to the excess precipitation and the reduced surface solar radiation that further reduces convection (in the Indian Ocean in particular) through a negative feedback and gives an apparent improvement in atmospheric biases (Levine et al. 2013). The water vapor content climatological difference is also similar to HadGEM2-A differences, except for the central Pacific where HadGEM2-ES shows a stronger dry climate. The dry biases over the western Pacific and the eastern Indian Ocean and the overall drier climatological conditions over the ocean are consistent with the NWP results.

The precipitation biases for both NWP and climate models are similar, and the water vapor bias trends in NWP drift to the model climatological values gradually, implying that precipitation has a quick response to the parameterization processes but that the water vapor has a slow response. The clear link between the NWP model bias and the systematic bias in its climatemodel version means that the bias evolution in the
NWP model in the first few days can therefore be informative for the understanding of the processes responsible for these biases.

\section{Simulated and observed precipitation variability}

The mean precipitation and water vapor content for June-September 2011 over the tropical oceans and land from both the NWP model and observations are plotted in Fig. 8. All lines are 3-day running means. Over the tropical ocean, both precipitation and water vapor content from the NWP model have larger values than are observed, but variability is well represented.

Over the tropical land, mean precipitation between forecasts (mean values are 3.0, 3.1, and $3.2 \mathrm{~mm} \mathrm{day}^{-1}$ for days 0,1 , and 2 , respectively) and TMPA data (mean value is $3.0 \mathrm{~mm} \mathrm{day}^{-1}$ ) is comparable and in phase (Fig. 8b). The correlation coefficients $r$ are 0.61 and 0.52 for the first two days, and $r$ drops quickly for the third day $(r=0.18)$. Although the water vapor contents from NWP model forecasts are systematically higher than those from ERA-Interim, there is very good agreement between them, and the correlation coefficients are respectively $0.95,0.77$, and 0.45 for the first three days of NWP forecasts. The correlation coefficients in Table 3 are very high at day 0 because the RSS F17 water vapor is assimilated into the model.

The combined zonal mean precipitation variation of 0000 and 1200 UTC with latitude and time over the western Pacific is plotted in Fig. 9. There is very good agreement of the variability between TMPA and NWP data. The pattern can even be forecast well at day 5 . The agreement over the Atlantic is also very good (supplemental Fig. S6); the general pattern can be captured well at day 0 but becomes weaker at day 5 .

The predicted northward propagation of the precipitation from NWP over the western Pacific and Atlantic is associated with tropical storms and is shown in Fig. 10. (The storm name and path data were obtained online from http://www.wunderground.com.) The storm path is colored on the basis of its wind speed intensity $\left(\mathrm{mi} \mathrm{h}^{-1}\right.$; $1 \mathrm{mi} \mathrm{h}^{-1} \approx 0.447 \mathrm{~m} \mathrm{~s}^{-1}$ ).

It is clear that when the tropical storm is formed over the western Pacific Ocean it carries the precipitation away from the ITCZ when moving northward. This pattern indicates the importance of tropical cyclones in determining zonal precipitation anomalies and merits further investigation in the future.

\section{Summary}

The NWP precipitation dataset from the Met Office global forecast model is compared with those from 
Tropical P (mm/day)

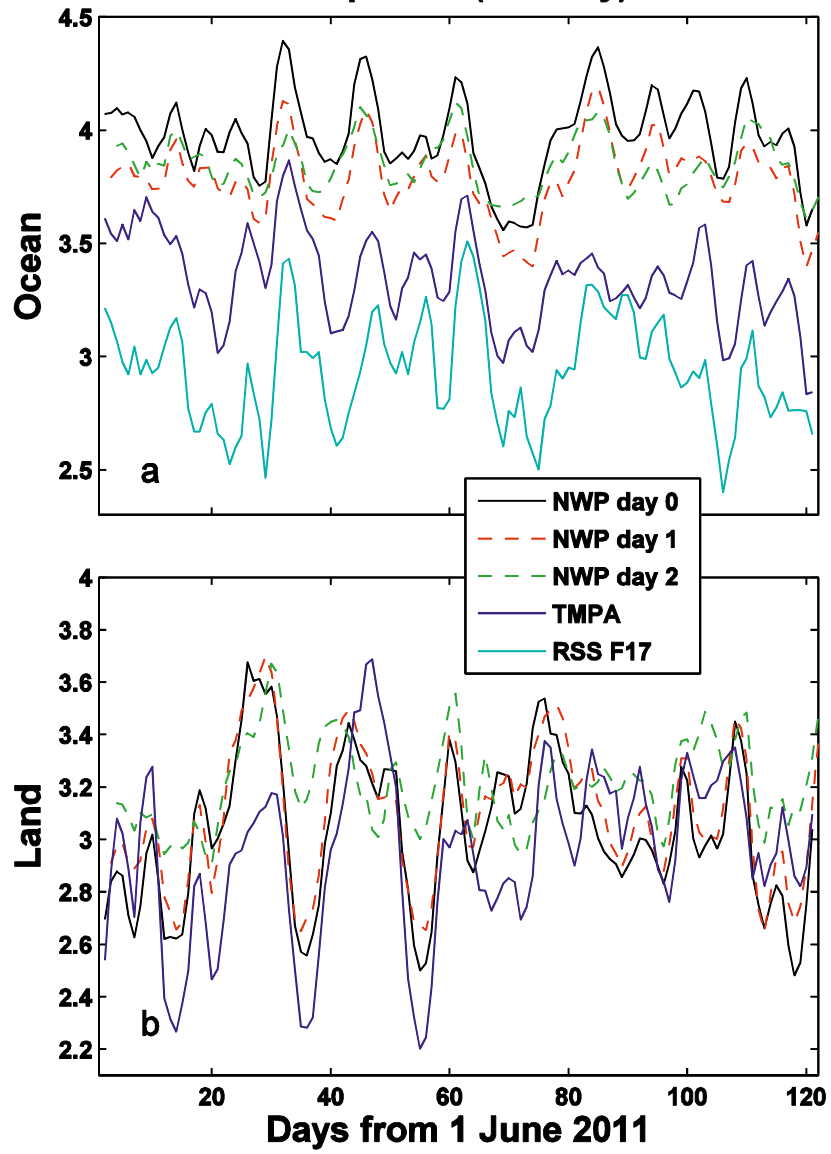

Tropical WV (mm)

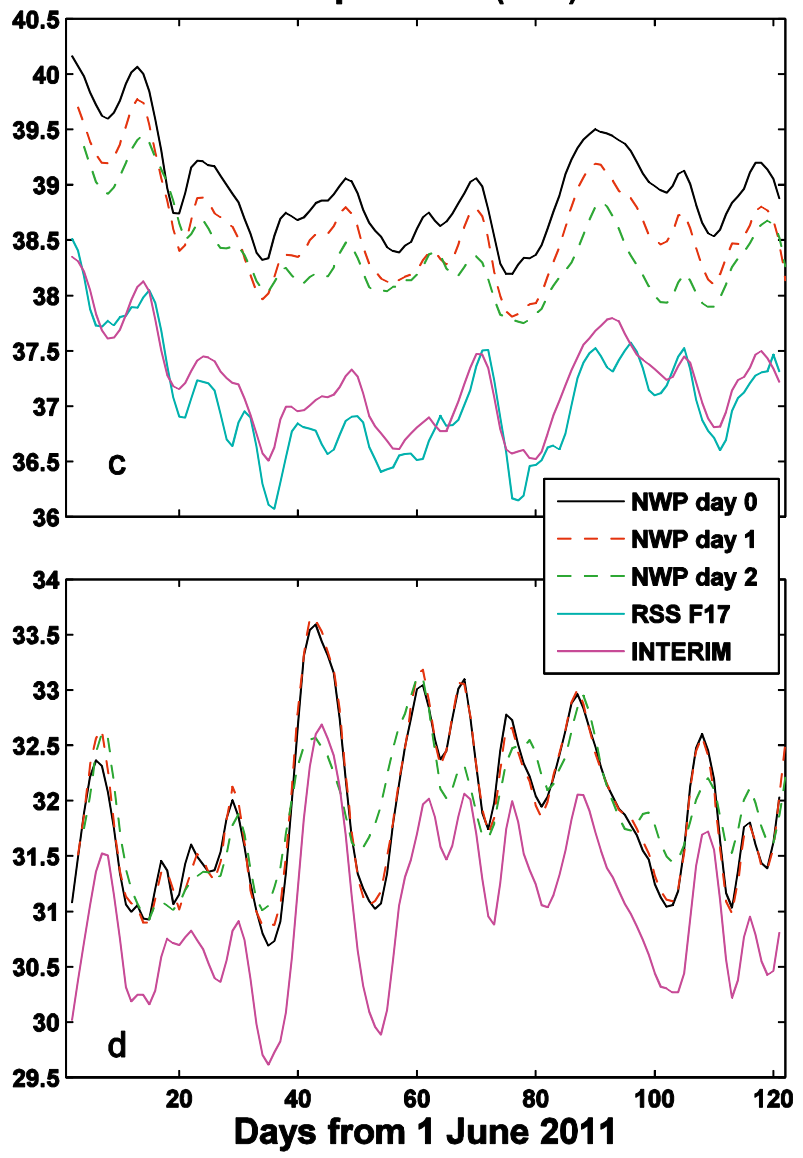

FIG. 8. Time series of (a),(b) mean precipitation and (c),(d) water vapor content over the tropical (top) oceans and (bottom) land. All lines are 3-day running means.

satellite observations (RSS F17 and TMPA) to assess the skill of the NWP model and to assess the suitability of NWP simulations in providing information on the physical processes leading to the development of systematic biases in climate-model simulations. Global mean features, such as the ITCZ, are captured well by the model, and the tropical storm paths over both the western Pacific and Atlantic are forecast well, particularly over the western Pacific warm pool where the tropical storm path can be forecast well even at day 5. The daily mean variability of precipitation and water vapor content over the tropical ocean and the tropical land are also forecast well, particularly for precipitation over tropical land for which both magnitude and phase from the NWP model are very close to the observations.

A precipitation diurnal cycle is identified in simulations and observations over the tropical oceans with a simulated peak in the early morning $(\sim 0100-0600$ LT)

TABLE 3. Temporal correlation coefficients $r$ of precipitation and water vapor content between datasets.

\begin{tabular}{|c|c|c|c|c|}
\hline Precipitation & NWP day 0 & NWP day 1 & NWP day 2 & TMPA \\
\hline Tropical ocean TMPA & 0.65 & 0.44 & 0.13 & - \\
\hline Tropical ocean RSS F17 & 0.59 & 0.41 & 0.02 & 0.68 \\
\hline Tropical land TMPA & 0.61 & 0.52 & 0.18 & - \\
\hline Water vapor content & NWP day 0 & NWP day 1 & NWP day 2 & RSS F17 \\
\hline Tropical ocean RSS F17 & 0.90 & 0.81 & 0.69 & - \\
\hline Tropical ocean ERA-Interim & 0.97 & 0.90 & 0.75 & 0.93 \\
\hline Tropical land ERA-Interim & 0.95 & 0.77 & 0.45 & - \\
\hline
\end{tabular}




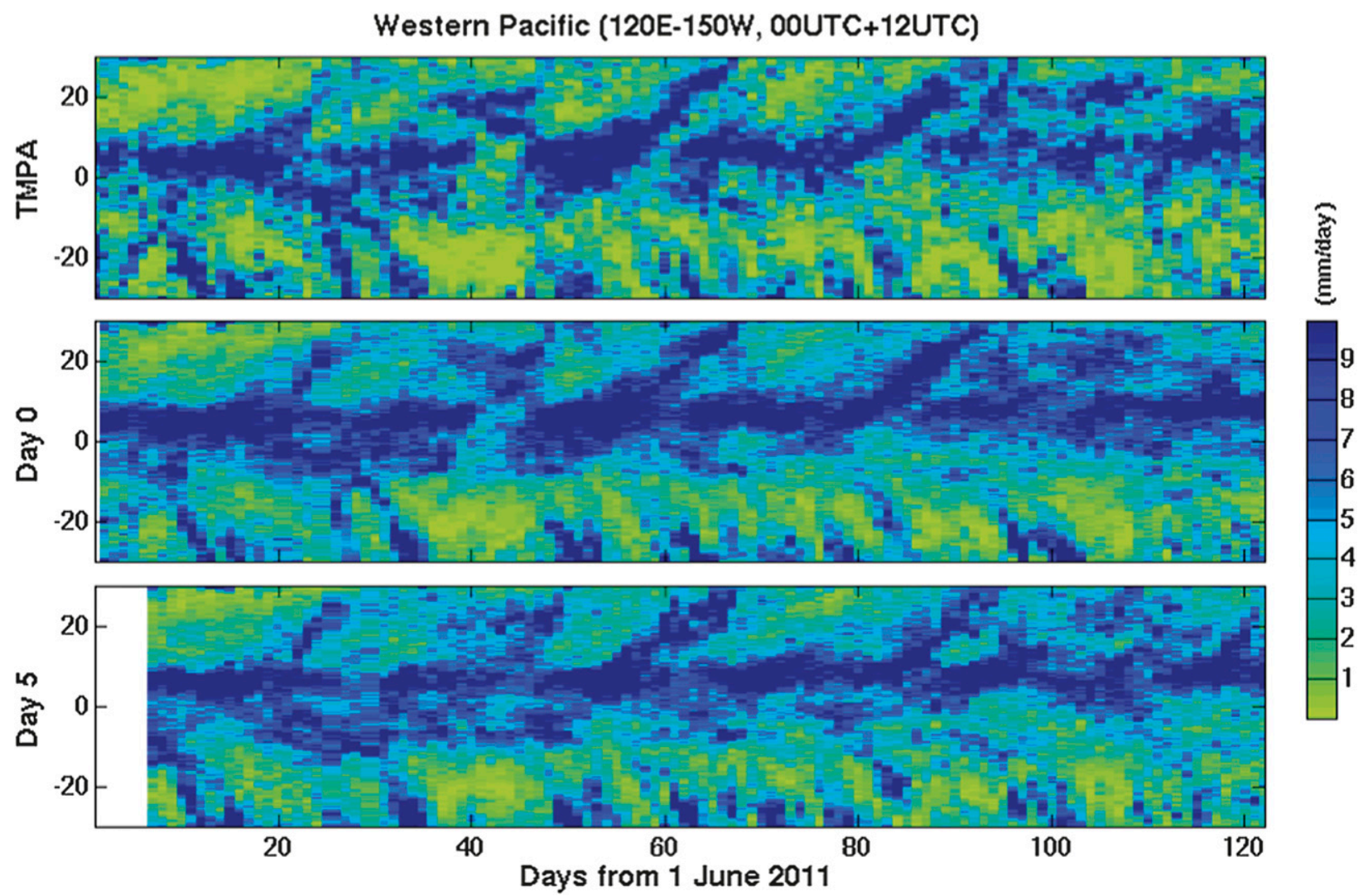

FIG. 9. Western Pacific zonal mean precipitation variation $\left(\mathrm{mm} \mathrm{day}^{-1}\right)$ from TMPA and from the NWP model at day 0 and day 5 . The data are the mean of precipitation at 0000 and 1200 UTC.

and the observed peak up to $3 \mathrm{~h}$ behind; the modeled amplitude is much higher than the observed ones. Precipitation occurs too early in the model over land, consistent with previous studies (Slingo et al. 2003; Kendon et al. 2012; Stratton and Stirling 2012). The peak time is around 1500-1800 LT over tropical land in the observations, but it is around $1200 \mathrm{LT}$ in the NWP model. The simulated mean diurnal phase is stable with the forecast lead time over the area considered. All of these results suggest a too-rapid response of the convective parameterization to the diurnal cycle in surface fluxes, indicating either a weakness in the convective triggering procedure or the turbulent and convective mixing of the atmosphere (Bechtold et al. 2004).

Most of the biases over land areas can be explained by the phase difference of the diurnal cycle, such as the dry biases over Central America and Africa at 0000 UTC and the wet bias over Africa and the dry bias over South Asia at 1200 UTC. There is a bimodal variation of diurnal cycle over Australia in the observations, but there is only one peak in the model. The bias is still small because of the small diurnal-cycle amplitude in that region.
The major biases-in particular those over the western Pacific and the central Indian Ocean-can be linked between the NWP and climate versions of the Met Office model. The adjustment of precipitation bias from the first day to the second day is substantial, in particular over the northwestern subtropical Pacific, and is associated with the model drift to its climatological values as determined from climate-model simulations. Since the period is limited to the Northern Hemisphere summer, the biases may be region dependent [e.g., the annual mean difference is shown by Brown et al. (2012)].

The biases associated with the diurnal cycle are the main sources of the forecast errors. A recent study by Stratton and Stirling (2012) shows that changing the deep convective parameterization can improve both the amplitude and timing of the diurnal peak in precipitation over land. It will be interesting to see the improvement of the NWP model by employing this new scheme in the future. Only the precipitation events relating to high-frequency (diurnal cycle) and synoptic (tropical cyclones) time scales are investigated in this paper by using data for 4 months. Although some interesting results have been obtained, it will be useful to 


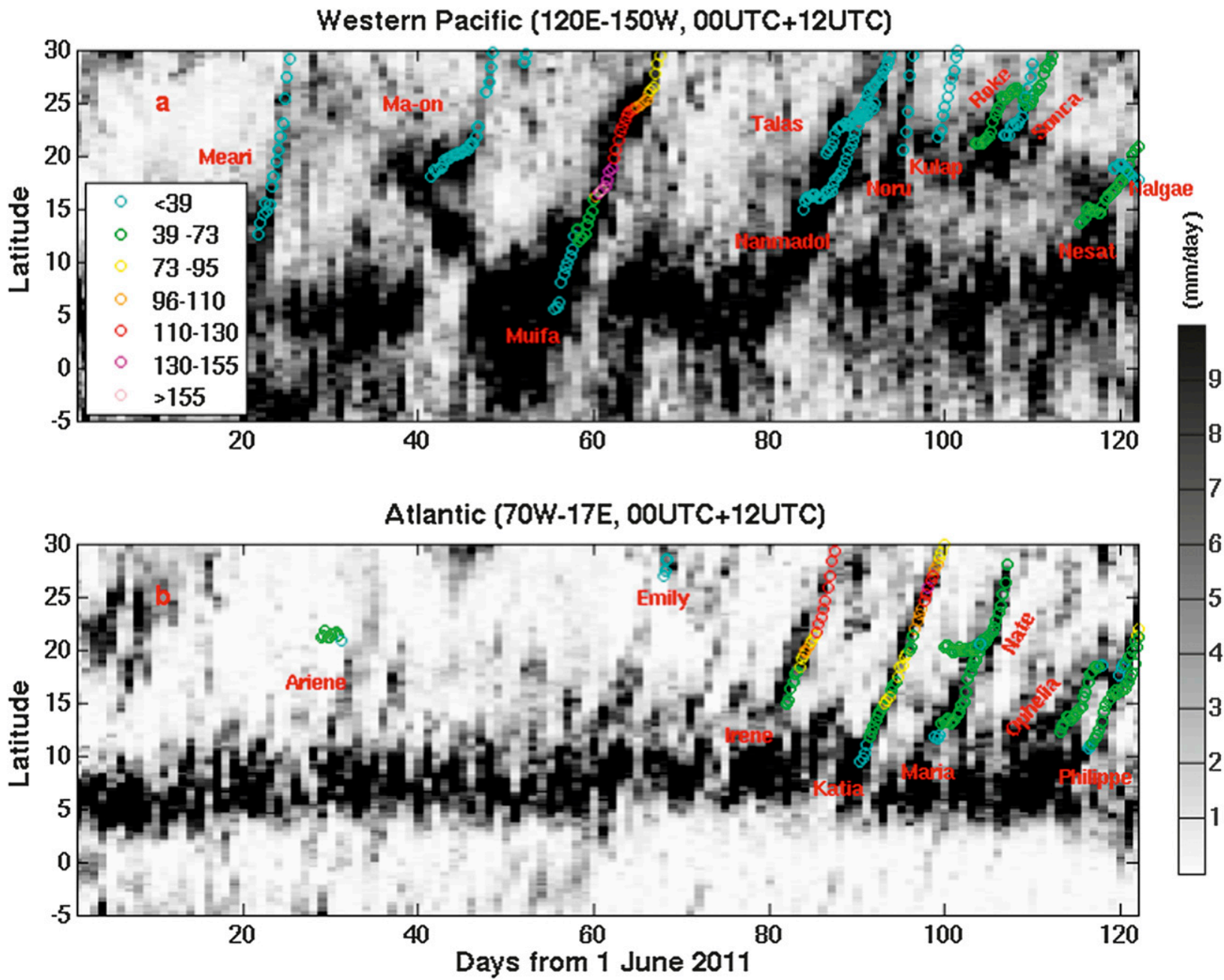

FIG. 10. NWP zonal mean precipitation variation $\left(\mathrm{mm} \mathrm{day}^{-1}\right)$ with latitude and time at day 0 over the (a) western Pacific and (b) Atlantic, together with the tropical storm path, which is colored on the basis of its wind speed intensity in miles per hour.

use a longer period of data to check the statistical robustness of these results and to consider low-frequency modes, such as the Madden-Julian oscillation, in a future study (Rasch et al. 2006).

Acknowledgments. This work was undertaken as part of the PAGODA and PREPARE projects funded by the U.K. Natural Environmental Research Council under Grants NE/I006672/1 and NE/G015708/1 and was additionally supported by the National Centre for Earth Observations and the National Centre for Atmospheric Science. NWP data are provided by the Met Office. TMPA data were obtained online (http://mirador.gsfc.nasa.gov/). SSM/I and SSMIS products were also obtained online (ftp.ssmi.com). ERA-Interim data were obtained from ECMWF, and HedGEM2-A and HadGEM2-ES data are from the CMIP5 and AMIP5 datasets from the British
Atmospheric Data Centre (http://badc.nerc.ac.uk/home/ index.html) and the Program for Climate Model Diagnosis and Intercomparison (PCMDI; http://pcmdi3. llnl.gov/esgcet/home.htm). We acknowledge the World Climate Research Programme's Working Group on Coupled Modelling, which is responsible for CMIP, and we thank the climate-modeling groups whose models are listed in Table 1 for producing and making available their model output. For CMIP, the U.S. Department of Energy's PCMDI provided coordinating support and led the development of software infrastructure in partnership with the Global Organization for Earth System Science Portals. The scientists involved in the generation of these datasets are sincerely acknowledged. The data for tropical storms were obtained online (http:// www.wunderground.com). We sincerely thank the reviewers for their insightful comments, which have helped to improve the paper. 


\section{REFERENCES}

Allan, R. P., A. Slingo, S. F. Milton, and M. A. Brooks, 2007: Evaluation of the Met Office global forecast model using Geostationary Earth Radiation Budget (GERB) data. Quart. J. Roy. Meteor. Soc., 133, 1993-2010.

_, C. Liu, M. Zahn, D. A. Lavers, E. Koukouvagias, and A. Bodas-Salcedo, 2013: Physically consistent responses of the global atmospheric hydrological cycle in models and observations. Surv. Geophys., doi:10.1007/s10712-012-9213-z, in press.

Bechtold, P., J.-P. Charoureau, A. Beljaars, A. K. Betts, M. Kohler, M. Miller, and J.-L. Redelsperger, 2004: The simulation of the diurnal cycle of convective precipitation over land in a global model. Quart. J. Roy. Meteor. Soc., 130, 3119-3137.

Bergman, J. W., and M. L. Salby, 1996: Diurnal variations of cloud cover and their relationship to climatological conditions. J. Climate, 9, 2802-2819.

Brown, A., S. Milton, M. Cullen, B. Golding, J. Mitchell, and A. Shelly, 2012: Unified modeling and prediction of weather and climate: A 25-year journey. Bull. Amer. Meteor. Soc., 93, 1865-1877.

Chakraborty, A., 2010: The skill of ECMWF medium-range forecasts during the Year of Tropical Convection 2008. Mon. Wea. Rev., 138, 3787-3805.

Clayton, A. M., A. C. Lorenc, and D. M. Barker, 2012: Operational implementation of a hybrid ensemble/4D-Var global data assimilation system at the Met Office. Quart. J. Roy. Meteor. Soc., 139, 1445-1461.

Dai, A., 2001: Global precipitation and thunderstorm frequencies. Part II: Diurnal variations. J. Climate, 14, 1112-1128.

— , and K. E. Trenberth, 2004: The diurnal cycle and its depiction in the Community Climate System Model. J. Climate, 17, 930-951.

—_ X. Lin, and K. L. Hsu, 2007: The frequency, intensity, and diurnal cycle of precipitation in surface and satellite observations over low- and mid-latitudes. Climate Dyn., 29, 727-744.

Dee, D. P., and Coauthors, 2011: The ERA-Interim reanalysis: Configuration and performance of the data assimilation system. Quart. J. Roy. Meteor. Soc., 137, 553-597.

Hilburn, K. A., and F. J. Wentz, 2008: Intercalibrated passive microwave rain products from the Unified Microwave Ocean Retrieval Algorithm (UMORA). J. Appl. Meteor. Climatol., 47, 778-794.

Huffman, G. J., and Coauthors, 2007: The TRMM Multisatellite Precipitation Analysis (TMPA): Quasi-global, multiyear, combined-sensor precipitation estimates at fine scales. $J$. $H y$ drometeor., 8, 38-55.

John, V. O., and B. J. Soden, 2007: Temperature and humidity biases in global climate models and their impact on climate feedbacks. Geophys. Res. Lett., 34, L18704, doi:10.1029/ 2007GL030429.

Kendon, E. J., N. M. Roberts, C. A. Senior, and M. J. Roberts, 2012: Realism of rain fall in a very high-resolution regional climate model. J. Climate, 25, 5791-5806.

Kharin, V. V., F. W. Zwiers, X. Zhang, and G. C. Heger, 2007: Changes in temperature and precipitation extremes in the IPCC ensemble of global coupled model simulations. J. Climate, 20, 1419-1444.

Kidd, C., E. Dawkins, and G. Huffman, 2013: Comparison of precipitation derived from the ECMWF operational forecast model and satellite precipitation datasets. J. Hydrometeor., 14, 1463-1482.

Kikuchi, K., and B. Wang, 2008: Diurnal precipitation regimes in the global tropics. J. Climate, 21, 2680-2696.
Kummerow, C., and Coauthors, 2001: The evolution of the Goddard profiling algorithm (GPROF) for rainfall estimation from passive microwave sensors. J. Appl. Meteor., 40, 1801-1820.

Levine, R. C., A. G. Turner, D. Marathayil, and G. M. Martin, 2013: The role of northern Arabian Sea surface temperature biases in CMIP5 model simulations and future projections of Indian summer monsoon rainfall. Climate Dyn., 41, 155-172.

Liu, C., and R. P. Allan, 2013: Observed and simulated precipitation responses in wet and dry regions 1850-2100. Environ. Res. Lett., 8, 034002, doi:10.1088/1748-9326/8/3/034002.

- — - and G. J. Huffman, 2012: Co-variation of temperature and precipitation in CMIP5 models and satellite observations. Geophys. Res. Lett., 39, L13803, doi:10.1029/2012GL052093.

Martin, G. M., S. Milton, C. Senior, M. Brooks, S. Ineson, T. Reichler, and J. Kim, 2010: Analysis and reduction of systematic errors through a seamless approach to modeling weather and climate. J. Climate, 23, 5933-5957.

, and Coauthors, 2011: The HadGEM2 family of Met Office Unified Model Climate configurations. Geosci. Model Dev., 4, 723-757.

Meehl, G. A., and Coauthors, 2007: Global climate projections. Climate Change 2007: The Physical Science Basis, S. Solomon et al., Eds., Cambridge University Press, 747-846.

O'Gorman, P. A., 2012: Sensitivity of tropical precipitation extremes to climate change. Nat. Geosci., 5, 697-700.

— precipitation extremes in simulations of 21st-century climate change. Proc. Natl. Acad. Sci. USA, 106, 14773-14777.

Pearson, K. J., G. M. S. Lister, C. E. Birch, R. P. Allan, R. J. Hogan, and S. J. Woolnough, 2013: Modelling the diurnal cycle of tropical convection across the 'grey zone.' Quart. J. Roy. Meteor. Soc., doi:10.1002/qj.2145, in press.

Pierce, D. W., T. P. Barnett, E. J. Fetzer, and P. J. Gleckler, 2006: Three-dimensional tropospheric water vapor in coupled climate models compared with observations from the AIRS satellite system. Geophys. Res. Lett., 33, L21701, doi:10.1029/ 2006GL027060.

Power, S. B., F. Delage, R. Colman, and A. Moise, 2012: Consensus on twenty-first-century rainfall projections in climate models more widespread than previously thought. J. Climate, 25, 3792-3809.

Rasch, P. J., and Coauthors, 2006: A characterization of tropical transient activity in the CAM3 atmospheric hydrologic cycle. J. Climate, 19, 2222-2242.

Rawlins, F., S. P. Ballard, K. J. Bovis, A. M. Clayton, D. Li, G. W. Inverarity, A. C. Lorenc, and T. J. Payne, 2007: The Met Office global four-dimensional variational data assimilation scheme. Quart. J. Roy. Meteor. Soc., 133, 347-362.

Rodwell, M. J., and T. N. Palmer, 2007: Using numerical weather prediction to assess climate models. Quart. J. Roy. Meteor. Soc., 133, 129-146.

Scheff, J., and D. M. W. Frierson, 2012: Robust future precipitation declines in CMIP5 largely reflect the poleward expansion of model subtropical dry zones. Geophys. Res. Lett., 39, L18704, doi:10.1029/2012GL052910.

Slingo, J. M., P. Inness, R. Neale, S. Woolnough, and G.-Y. Yang, 2003: Scale interactions on diurnal to seasonal timescales and their relevance to model systematic errors. Ann. Geophys., 46, $139-155$.

Stratton, R. A., and A. J. Stirling, 2012: Improving the diurnal cycle of convection in GCMs. Quart. J. Roy. Meteor. Soc., 138, 1121-1134.

Sun, Y., S. Solomon, S. Dai, and R. W. Portmann, 2007: How often will it rain? J. Climate, 20, 4801-4818. 
Taylor, C. M., R. A. M. de Jeu, F. Guichard, P. P. Harris, and W. A. Dorigo, 2012: Afternoon rain more likely over drier soils. Nature, 489, 423-426.

Taylor, K. E., R. J. Stouffer, and G. A. Meehl, 2012: An overview of CMIP5 and the experiment design. Bull. Amer. Meteor. Soc., 93, 485-498.

Walters, D. N., and Coauthors, 2011: The Met Office Unified Model Global Atmosphere 3.0/3.1 and JULES Global Land 3.0/3.1 configurations. Geosci. Model. Dev, 4, 919-941.

Williams, C. J. R., R. P. Allan, and D. R. Kniveton, 2012: Diagnosing atmosphere-land feedbacks in CMIP5 climate models. Environ. Res. Lett., 7, 044003, doi:10.1088/ 1748-9326/7/4/044003.

Williams, K. D., and M. E. Brooks, 2008: Initial tendencies of cloud regimes in the Met Office unified model. J. Climate, 21, 833-840.

Xie, S., H. Ma, J. Boyle, S. Klein, and Y. Zhang, 2012: On the correspondence between short- and long-time-scale systematic errors in CAM4/CAM5 for the Year of Tropical Convection. J. Climate, 25, 7937-7955.

Yang, G. Y., and J. M. Slingo, 2001: The diurnal cycle in the tropics. Mon. Wea. Rev., 129, 784-801. 